\title{
Interculturalidade: construção de um pensamento pós-abissal*
}

\author{
Interculturalidad: construcción de un pensamiento post-abisal \\ Interculturality: building a post-abyssal thinking \\ Isabella Vieira Barboza 1 Adolfo Ramos Lamar² \\ Recibido: 21/11/2016 / Aprobado: 7/3/2017
}

\begin{abstract}
Resumo
Este trabalho visa a questionar a interculturalidade, com base no pensamento abissal e da colonialidade. Infelizmente, esse pensamento ainda está presente na Sociedade Brasileira não nos termos do acordo territorial, mas as negociações têm imposto a nossa sociedade e reproduzir continuamente. Hoje, esses pensamentos são apresentados no poder do racismo de maneiras diferentes. Portanto, para entender o tema deste trabalho, foi realizado um estudo da literatura para entender a raiz do pensamento abissal e sua relação com o multiculturalismo. Este estudo conclui que não há nenhuma maneira de separar o conceito de construção intercultural do conceito de um postabisal, capaz de superar o conceito de superioridade ou inferioridade pensamento. Transcender o pensamento mais multicultural, multiculturalismo incentiva uma interrupção das barreiras abissais, integrando grupos diferentes.
\end{abstract}

Palavras-chave: interculturalidade, pensamento pós-abissal, descolonialidade, colonialidade, epistemologia.

\section{Resumen}

\begin{abstract}
Este trabajo busca cuestionar el interculturalismo, basado en el pensamiento abismal y la colonialidad. Desafortunadamente, este pensamiento está todavía presente en la sociedade brasileña, no en virtud de los asentamientos territoriales, pero las negociaciones se han impuesto a nuestra sociedad y reproducir continuamente. Hoy en día este tipo de pensamientos, se presentan en el poder del racismo en diferentes maneras. Por lo tanto, para entender el tema de este trabajo, hemos realizado un estudio de la literatura para entender la raíz del pensamiento abismal y su relación con la interculturalidad. De este estudio se concluye que no hay manera de separar el concepto de interculturalidad de la construcción del concepto de un pensamiento postabisal, capaz de superar la concepción de superioridad o inferioridad. Al transcender más el pensamiento multicultural, la interculturalidad fomenta una interrupción de las barreras abisales mediante la integración de los diferentes grupos.
\end{abstract}

Palabras-clave: interculturalidad, pensamiento postabisal, decolonialidad, colonialidad, epistemología.

\footnotetext{
* Este texto corresponde con la temática de la ponencia presentada en el III Seminario Internacional Culturas y Desarrollo, III Encuentro de la Red de Interculturalidad, IV Encuentro de la Red de Trabajo con Pueblos Indígenas, IV Encuentro sobre Sociedades en Cambio, Territorios, Culturas y Buen Vivir, Desafíos desde las identidades y Saberes Diversos, realizado el 20, 21 y 22 de julio de 2016, en la Universidad Nacional, campus Omar Dengo, Heredia y en la Universidad de Costa Rica, Sede de Occidente, San Ramón, ahora en formato de artículo científico, en versión completa extendida.

${ }^{1}$ Graduada en Pedagogía en la Universidad del Valle de Itajaí (UNIVALI), especialista en Educación Infantil y Desarrollo, por la Universidad Cándido Mendes. Magister del Programa de Postgrado en Educación de la - FURB en la Línea de Investigación Lenguaje y Educación. Becario de Postgrado CAPES de la Fundación Universidad Regional de Blumenau (FURB), Brasil. Correo electrónico: Misvieira@gmail.com

${ }^{2}$ Posdoctorado en Filosofía de la Educación por la Universidad de São Paulo (USP). Doctor en Educación por la Universidad Estatal de Campinas (UNICAMP) y Magister en Política Científica y Tecnológica - UNICAMP. Licenciado en Filosofía por la Universidad de la Habana (Cuba). Profesor en la Universidad Regional de Blumenau (FURB) en la Línea de Investigación Filosofía y Educación - EDUCOGITANS, Brasil. Correo electrónico: Ajemabra@yahoo.com.br
} 


\title{
Abstract
}

\begin{abstract}
This study pretends to question the term interculturalism based on abyssal thinking and colonialism. This way of thinking is still present in Brazilian society, not by territorial settlements, but by negotiations that have been imposed on our society that has been reproduced through time. Today, these thoughts have been remained in the power of racism performed in different ways. Besides, a literature review shows that there is no way to separate the word intercultualism from its construction based on the idea of post-abyssal thinking. To be able to overcome feelings of superiority or inferiority, that is, beyond a multicultural thought, interculturalism promotes intercultural thoughts that may break the abyssal barriers by integrating different groups.
\end{abstract}

Keywords: interculturalism, post-abyssal thinking, descolonialidad, colonialismo, epistemology.

\section{O princípio}

Ao problematizar as possíveis relações do pensamento abissal e da colonialidade relacionadas à interculturalidade, precisamos nos remeter às origens que proporcionaram tais pensamentos. Isto porque, ao falarmos de interculturalidade é quase automático nos remetermos e lembrarmo-nos dos grupos minoritários que por muitas vezes acabam excluídos socialmente. Afinal, como definir a interculturalidade se não como parte de um processo pelo qual se possibilita a integração de pessoas de culturas diferentes que ao longo de toda uma história têm sido excluídos socialmente e muitas vezes até esquecidos. Remeter-nos a interculturalidade, significa remeter-nos a temas que se relacionam a esses grupos minoritários que ao longo da história tem batalhado pelo seu reconhecimento, bem como falar das relações de poder que os sujeitaram e os anularam. Ao pensarmos em interculturalidade, começamos a nos lembrar das práticas que surgiram nas últimas décadas, tentando retirar da exclusão e dos guetos da sociedade os grupos excluídos por esta mesma sociedade. Grupos como os afro-brasileiros, indígenas e imigrantes, que conforme Santos (2007) ressalta, encontram-se invisibilizados perante aos grupos majoritários, em lados opostos de uma linha abissal. A linha abissal é um dos pontos do qual a interculturalidade e esse trabalho irão tratar, mas não será o único. Ao falarmos de interculturalidade, não devemos nos restringir apenas a essa relação entre pensamentos abissais e excludentes e a interculturalidade por meio desta divisão de grupos e de classes sociais, o tema nos permite ir além. A interculturalidade passa necessariamente por essas minorias excluídas assim instituídas através das relações de poder impostas pela sociedade na qual elas se encontram. Mas a interculturalidade avança para além das divergências e dicotomias presentes nessa sociedade moderna de hoje, desses abismos coloniais criados ao longo da história e as bases epistemológicas que sustentam tais pensamentos abissais.

O pensamento atual do mundo globalizado pode ser chamado de abissal (Santos, 2007). Autores como Boaventura Sousa Santos, ao abordar o assunto, justificam a opção pelo termo abissal por este dar uma ideia de divisão entre grupos de uma mesma sociedade em duas linhas de frente diferentes, linhas separadas por uma espécie de abismo que fora construído socialmente, mas que conscientemente nem sempre é reconhecido por todos. Aos lados do precipício, estariam as diferentes colonizações, os grupos de pensamentos divergentes que separados por esse abismo de dúvidas, incertezas e preconceitos se afastam. Essa é uma divisão que acaba por restringir a guetos uma parcela da sociedade dita como "inferior" ou como "diferente". "A característica fundamental do pensamento abissal é a impossibilidade da copresença dos dois lados da linha" (Santos, 2007, p. 71).

Boaventura Sousa Santos (2007) explica também que nem todas as formas de pensamento abissal estão necessariamente vinculadas ao 
pensamento ocidental. "Não pretendo que o pensamento moderno ocidental seja a única forma de pensamento abissal. Pelo contrário, é muito provável que existam, ou tenham existido, formas de pensamento abissal fora do Ocidente" (2007, p. 3).

Podemos assim então, definir o pensamento abissal como a impossibilidade de que esses grupos diferentes possam conviver harmonicamente de um mesmo lado. Entretanto, esse ponto de vista de grupos sociais em lados opostos de uma linha divisória, só existe por causa das convenções sociais criadas que acabam por criar rótulos para grupos distintos e possibilita que um desses grupos, através da imposição de sua dita superioridade, imponha a sua força, nem sempre física, tentando apagar a existência do outro e dos artefatos culturais e crenças produzidos pelo outro lado da linha abissal, tentando assim, minimizar a presença que é alheia a sua. Tornando então, o outro lado marginalizado.

\section{O Pensamento Abissal}

Não podemos prosseguir em uma discussão sobre interculturalidade através da ideia de descolonialidade e de um pensamento pós-abissal, sem aprofundar um pouco mais essa condição abissal na qual as duas linhas opostas se encontram e divergem, bem como sem abordar com maior profundidade a ideia e os conceitos que abarcam a colonialidade e, por conseguinte a descolonialidade. Uma vez que, através dessa compreensão poderemos começar a compreender quais são as possíveis razões que dividem seres culturais, em suas singularidades e heterogeneidades em lados diversos, menosprezando seus valores e crenças e restringindo-os a rótulos que desprezam toda a sua consciência sociocultural. Visto que compreendemos que somos todos sujeitos sociais, históricos, pensantes, comunicantes e transformadores, capazes de assumirmos a nós mesmos, sem excluir o outro (Freire, 2002).
Essa linha abissal que divide socialmente diferentes grupos seja por sua religião, condição econômica ou até mesmo suas opções sexuais ou políticas se instituem através de relações de poder de uma sociedade. É impossível negar as ideologias por trás dos discursos presentes tanto nas organizações, mas especialmente nos sujeitos que delas fazem parte. Apesar de muitas vezes esses discursos se apresentarem de formas quase invisíveis, são discursos embasados em valores, instituídos na sua personalidade e formação como sujeito e que se tornam partes inegáveis e constituintes da singularidade e da pessoalidade de cada um. Valores estes, que foram transmitidos por suas famílias, pelos meios aos quais estiveram expostos: tenham sido eles, religiosos, políticos ou até mesmo influenciados pela ausência de influência de algum destes ambientes.

Somos seres constituídos historicamente, influenciados pelo local e momento histórico do qual fazemos parte, consequentemente o momento e o local do qual fazemos parte é constituinte da personalidade e das crenças de cada sujeito. Desta forma, alguns sujeitos acabam por desconsiderar, menosprezando assim, aqueles que por uma origem sócio-histórica diferente, acaba por considerar outros valores como seus.

Quijano (2005) destaca que foi a formação das relações sociais produzidas na América, que instituíram novas identidades sociais. No início, essas identidades indicavam apenas a procedência geográfica, ou origem, mas com o tempo começaram a ganhar conotações raciais.

E na medida em que as relações sociais que se estavam configurando eram relações de dominação, tais identidades foram associadas às hierarquias, lugares e papéis sociais correspondentes, com constitutivas delas, e, consequentemente, ao padrão de dominação que se impunha. Em outras palavras, raça e identidade racial foram estabelecidas como instrumentos de classificação social básica da população (Quijano, 2005, p.107). 
O pensamento abissal moderno, como ressalta Boaventura Sousa Santos (2007, p.72), "se destaca pela capacidade de produzir e radicalizar distinções". $\mathrm{O}$ autor utiliza o termo radicalizar, pois além de produzir rótulos sociais para diferenciar os sujeitos, esses rótulos acabam por extremar as diferenças, apresentando-as como algo negativo, hierarquizado, onde uma qualidade se sobrepõe a outra. Tal pensamento reforça conceitos que intercedem por um ou outro lado da linha, tornando muitas de suas posições extremadas, embasando todas as invisíveis distinções e construções sociais que reforçam e dividem os dois lados da linha.

A noção de verdadeiro ou falso vista e constituída na ciência, ao longo do tempo se fortaleceu ao atender critérios materiais e conseguir classificar em bom ou ruim, conceitos, técnicas e objetos. Mas ao inseri-la no contexto social, ela demonstra um lado do pensamento abissal. Pois ao falarmos de sociedade e cultura, vimos que boa parte da sociedade é colocada a margem do dito "normal" apenas por constituições sociais que foram fundadas e corroboradas por personagens que vão à contramão da outra linha, relegando aos ditos "diferentes" uma posição de inferiorização. Apagando suas culturas e dando-lhe um grau de invisibilidade perante a sociedade, desvalorizando e menosprezando a importância de seus valores constituídos por fugirem das convenções sociais do senso comum e das próprias noções de verdadeiro ou falso. Entretanto, faz-se necessário sempre ressaltar, que os rótulos criados socialmente foram constituídos por sujeitos sociais inseridos na mesma comunidade que aqueles ditos diferentes, mas, entretanto, as relações de poder concederam a um dito grupo social, legitimando socialmente então, o poder a eles concedido. $\mathrm{O}$ assujeitamento de um grupo específico, nada mais é que a valorização de um outro grupo ante aquele.

Alguns desses valores culturais, chamados e rotulados como crenças e ou cultura, são comumente desvalorizados por aqueles que possuem um aparato do que a ciência ou a sociedade majoritária pactuam como pertinentes e substanciais. "O outro lado da linha alberga apenas práticas incompreensíveis, mágicas ou idolátricas" (Santos, 2007, p.8). Para os sujeitos do grupo majoritário, esses valores culturais dos grupos minoritários não passam de crendices, opiniões, magia, idolatria ou hipóteses. Não são factuais, confiáveis ou ponderados. São descartáveis, tais como muitas vezes são da mesma forma tratados os seus sujeitos. Novamente, nos remetemos à história para compreender que tais valores $\mathrm{e}$ crenças são continuamente transformados, e que tais padrões estabelecidos respeitam a um contexto atual de poder, onde o que hoje é considerado forte prevalece sobre o grupo minoritário, impondo a ele os seus valores, os seus conceitos e sua cultura. Contudo, nem sempre esses valores, crenças e ideologias irão permanecer apenas pelo tempo histórico no qual fora imposto. Muitas vezes os valores e $\mathrm{o}$ assujeitamento transcendem o momento histórico, resultando em rejeições e discriminações arraigadas a sociedade.

Tudo que não ocorre dentro dos parâmetros pré-estabelecidos socialmente para o lado da linha dita majoritária, é desconsiderado e descartado. São inúmeras as possibilidades de conhecimentos, valores e sujeitos desprezados por convenções sociais de origem colonialista que define que na sociedade existem dicotomias que devam ainda hoje, no mundo moderno e globalizado, prevalecer. Divisões como: o certo e errado, o verdadeiro e falso, o legal e o ilegal. As diferenças sociais, culturais e geográficas são descartadas, e a voz da maioria, aqui vista e apresentada não como maioria numérica, mas sim uma maioria privilegiada, constituída pelos considerados poderosos e influentes, sobrepõe-se sobre a minoria renegada. Mignolo (2005, p. 34) define a colonialidade "como o outro lado (o lado escuro?) da modernidade."

Aqui talvez caiba salientar, que ao falarmos de minoria, concordamos com Mello (1999, p. 38) ao defender que: "entende-se por minoria um grupo de pessoas que forma uma comunidade étnica de menor prestígio e status em relação às demais pessoas que vivem em um determinado país ou comunidade". 
Grupo de pessoas este que não necessariamente é menor numericamente, tão pouco intelectualmente ou de qualquer outra espécie de classificação, mas um grupo social que se constitui socialmente como menos poderoso, e que abraçado neste conceito se torna subjugado por um grupo dito superior que utiliza de sua posição social para impor suas ideias e convicções aos demais grupos.

O colonialismo, herança cultural de nossa sociedade, "envolve conquista, e esta se objetivava na submissão das populações encontradas, na apropriação dos lugares, e na submissão dos poderes eventualmente defrontados" (Moraes, 2008, p.65). Mas não podemos ver o colonialismo apenas como um movimento de força e submissão através da mesma. É necessário lembrar que muitas vezes esse processo de dominação ocorre através dos discursos inferiorizantes dos colonizadores sob os colonizados. Aqui usamos o verbo ocorre no presente, haja vista que apesar da era colonial ter acabado, o pensamento ainda se constitui em nossa sociedade como algo vigente. Um pensamento que invade o colonizado e transforma-o em servo do colonizador, pois como ressalta Fanon (1965, p. 48) "não é possível submeter à servidão aos homens sem inferiorizá-los parte por parte" e é justamente essa a parte colonialista tétrica que ainda retumba em nossa sociedade.

Ao saímos da era colonial, herdamos culturalmente hábitos coloniais de subjugação de raça, de grupos étnicos, que dada àquela época eram considerados inferiores, ou menos valorizados, e que até hoje ainda não conseguiram restituir seus poderes e ser justamente, reconhecidos socialmente. É impossível desvincularmos o pensamento colonialista de pensamentos preconceituosos e racistas que encontramos hoje na sociedade dita globalizada, pois o pensamento colonialista "só concebe o sistema mundo moderno do ponto de vista de seu próprio imaginário", (Mignolo, 2005, p. 34) e "o racismo não é mais que a explicação emocional, afetiva, algumas vezes intelectual, dessa inferiorização" (Fanon, 1965, p. 48).
Então como ir contra esses valores pessoais e modificar esse abismo que separa a sociedade em conceitos de certo e errado, de belo ou bonito, de legal ou ilegal? A ideia para romper os paradigmas, não pode ser através da imposição pela força da presença do outro, do estranho, do novo. A proposta é integrar de forma igualitária, mas ao mesmo tempo natural os dois lados da linha, no meio. Nem no terreno sobre o qual uma das culturas detêm seus domínios, nem através do domínio estrangeiro. É ceder às intolerâncias e dar a possibilidade de conhecimento do novo, através de propostas que possibilitem ver o outro, o estrangeiro como um lado diferente da mesma sociedade e cultura da qual ele faz parte, entretanto nem mais, nem menos importante, apenas diferente.

Porém, outra pergunta que pode nos surpreender, é como ver o diferente e não espelhar nele as projeções as quais possuímos? Posto que, as nossas vozes não deixam de ser produto do ambiente social no qual estamos incluídos. Em uma sociedade preconceituosa e colonialista, como romper as correntes da segregação e possibilitar uma nova aproximação? "O respeito às diferenças e obviamente aos diferentes exige de nós a humildade" (Freire, 2002, p. 46) afinal, ver o diferente é atentar-nos para as singularidades e heterogeneidades. E aqui, destacamos que por mais singulares que possamos muitas vezes ser, nos tornamos produtos de uma sociedade que homogeneíza, disciplina e controla.

O que ao longo do tempo tem ficado para trás, é a importância das singularidades diante de um mundo globalizado. A conservação dos valores culturais milenares e desconhecidos aos tempos modernos de uma cultura de massa. A herança colonial, de povos europeus até então instituídos como os mais sábios, ricos e importantes, fora massificada, divulgada e mundialmente propagada. Até hoje encontramos rescaldos dessas concepções de superioridade, de primeiro mundo versus terceiro mundo. Do nacionalismo exacerbado de valorização caucasiana, não-judia ante os miscigenados e pardos ciganos ou os imigrantes colonos. Uma herança 
antecessora e precursora da americanização do século XX. Ideias de homogeneização que valorizam mais uma vez e reforçam os encaixes aos padrões pré-estabelecidos, desmerecendo os que não se modernizaram até alcançar tais objetivos. Ou ainda pior, relegando a uma realidade a margem da sociedade aqueles que de forma reacionária insistem em não se entregar às linhas de oposição, e cismam em contrariar o sistema com uma postura de resistência.

\section{A Resistência intercultural}

Santos (2007, p. 11) destaca que "A luta pela justiça social global deve, por isso, ser também uma luta pela justiça cognitiva global. Para ser bemsucedida, esta luta exige um novo pensamento, um pensamento pós-abissal". Se de um lado encontramos um pensamento abissal constituído ao longo de uma história de divisões de classes, de conceitos e preconceitos instituídos socialmente e que insistem em manter-se arraigados aos pilares da sociedade, por outro lado o mundo globalizado tem apresentado uma forma de resistência: a interculturalidade.

Desenvolver e incentivar a interculturalidade, não apenas transitando entre as diferentes culturas, mas estabelecendo relações entre elas, estabelecendo trocas e colaborações. Uma proposta que visa não apenas conhecer o diferente e admitir a sua existência do outro lado da linha, mas romper com a barreira e juntar os dois lados em um lado só. Integrar os dois lados da mesma sociedade. Fácil ao primeiro olhar, eis o verdadeiro desafio para a sociedade moderna. Encontrar possibilidades de utilizar não só ferramentas que possibilitem o contato com as diferentes culturais e eventos sociais, mas ao mesmo tempo resistir as barreiras colonialistas que ainda prevalecem na sociedade, que visam a propagação de uma realidade já posta, de forma preconceituosa, racista e segregadora. Ao pensarmos em cultura, nos referimos a valores que vão muito além do gostar ou não de objetos e pessoas. O conceito de cultura avança sobre valores pessoais, nas concepções de mundo, de existência e na capacidade individual de tolerar, de aceitar e de compreender, "É necessário que os novos projetos de Educação visem a interculturalidade como forma de integração das diferentes culturas, não para apagar ou substituir nenhuma cultura, mas que deve integrar, e reforçar” (Barbosa, 2015, p. 60)

Freire (1987) ressaltaria que para que essa relação de tolerância, de aceitação e compreensão possa ocorrer, faz-se necessário ser humilde para ouvir o outro. "A humildade exprime, [...] uma das raras certezas de que estou certo: a de que ninguém é superior a ninguém" (Freire, 2002, p. 46). Ao aceitar que não existam raças, culturas ou povos superiores a qualquer outro, será possível então, possibilitar uma relação dialógica que prevaleça sobre os préconceitos já instituídos, pois somente através da relação eu-tu, que ocorrerá esse encontro entre os homens.

Esta é a razão por que não é possível o diálogo entre os que querem a pronúncia do mundo e os que não a querem; entre os que negam aos demais o direito de dizer a palavra e os que se acham negados deste direito. É preciso primeiro que, os que assim se encontram negados do direito primordial de dizer a palavra, reconquistem esse direito, proibindo que este assalto desumanizante continue (Freire, 1987, p. 45 - grifos do autor)

Desta forma, Freire (1987) observa a impossibilidade de estabelecer um diálogo entre os homens, sem que essa relação dialógica seja respeitada. Sem que a visão subjugadora e preconceituosa seja obstruída por aqueles que buscam o seu reconhecimento social. Afinal, o seu reconhecimento, e o direito a palavra, tal como traz Paulo Freire, é um direito de todos. "O reconhecimento da persistência do pensamento abissal é, assim, a conditio sine qua non para começar a pensar e a agir para além dele" (Santos, 2007, p. 22 - grifos do autor), afinal apenas compreendendo as razões pelas quais tais pensamentos imperam e 
possuem força na sociedade, é que conseguiremos prosseguir superando as desigualdades estabelecidas ao longo do tempo, evitando assim incidir-nos nos mesmos erros. "Sem este reconhecimento, o pensamento crítico permanecerá um pensamento derivativo que continuará a reproduzir as linhas abissais, por mais anti-abissal que se autoproclame" (Santos, 2007, p. 22).

\section{Conclusão}

Acreditamos que a interculturalidade, mas do que uma forma de resistência é a possibilidade de uma transformação nos pensamentos postos na sociedade em que vivemos. Como sujeitos históricoculturais que somos não podemos compreender a sociedade e a realidade na qual vivemos como algo posto e terminado, faz-se necessária uma visão crítica-reflexiva sobre o que nos cerca, já que, como Freire ressalta, “[...] a História em que me faço com os outros e de cuja feitura tomo parte é um tempo de possibilidades e não determinismo" (FREIRE, 2002, p. 22). Compreender as barreiras abissais como algo definitivo e intransponível é se subordinar aos rótulos instituídos socialmente, sem buscar romper dialogicamente com os prejulgamentos.

A raiz da interculturalidade está ironicamente no pensamento abissal. Fruto dos pensamentos rancorosos e preconceituosos de uma era colonial, o pensamento abissal reflete ainda na sociedade do século XXI, com paradigmas a serem rompidos e estereótipos que renegam a valorização devida a diversos grupos e sujeitos sociais. Entretanto, esse mesmo arquétipo social que resultou no pensamento abissal, despertou também naqueles que não conformados com o determinismo, com os preconceitos deliberados dos outros, resolveram de alguma forma resistir e através da interculturalidade combater as desumanidades instituídas ao longo do século.

Ao ver todos os sujeitos como iguais perante aos direitos e deveres, instituímos que somos todos iguais nas nossas diferenças, onde cada cultura, valores, opções e singularidades nos tornam apenas diferentes e enriquecem a sociedade onde vivemos. "Somente através da relação entre os diferentes sujeitos e o respeito mútuo às suas culturas e histórias, é que as visões etnocêntricas de superioridade de credos, classes sociais e raças poderão ficar para trás" (Barbosa, 2015, p. 62).

Para resistir interculturalmente requerse a necessidade de uma relação dialógica, de compreensão e reconhecimento ao outro. Humildade e amor ao próximo, perpassando pelo respeito às diferenças e a compreensão de um mundo plural, formado por seres humanos socioculturais distintos, onde há diferença acrescenta, e não deve jamais apartar os seres humanos. Uma vez que "Se não amo o mundo, se não amo a vida, se não amo os homens, não me é possível o diálogo" (Freire, 1987, p. 45).

\section{Referências}

Barbosa, I. (2015). Interculturalidade: Uma educação para a diversidade. In: XIII SImpósio integrado de pesquisa. FURB/UNIVILLE/UNIVALI, 13., 2015, Blumenau. Anais Blumenau: Furb, p. $55-63$.

"Ecologia de saberes: na direção de um novo paradigma científico?" Campinas, 29 set. 2008. Disponível em: <http://www.unicamp. br/unicamp/unicamp_hoje/ju/setembro2008/ ju411pdf/Pag11.pdf $>$. Acesso em: 01 ago. 2015.

Fanon, F. (1965). Racismo y cultura. En: Por la revolución africana. México: Fondo de Cultura Económica, p.38-52.

Freire, P. (2002). Pedagogia da autonomia. 25 ${ }^{\mathrm{a}}$ Ed. Rio de Janeiro: Paz e Terra.

Freire, P. (1987). Pedagogia do oprimido. 17a ed. Rio de Janeiro: Paz e Terra. 
MIgnolo, W. (2005). A colonialidade de cabo a rabo: o hemisfério ocidental no horizonte conceitual da modernidade. In: Lander, E. (2005). A colonialidade do saber: eurocentrismo e Ciências Sociais. Perspectivas latino-americanas. Buenos Aires: Colección Sur Sur, p. 33-49.

Moraes, A. (2008). Território e História no Brasil. 3a ed. Brasil São Paulo: Annablume.

Quijano, A. (2005). Colonialidade do poder, eurocentrismo e América Latina. In: Lander, E. (2005). A colonialidade do saber: eurocentrismo e Ciências Sociais. Perspectivas latino-americanas. Buenos Aires: Colección Sur Sur, p. 107-130.

Santos, B. (2007). "Para Além do Pensamento Abissal: Das linhas globais a uma ecologia de saberes". Novos Estudos, São Paulo, n. 79, p.71-94, nov. Disponível em: <http:// novosestudos.uol.com.br/>. Acesso em: 01 ago. 2015.

Santos, B. (2004). A universidade no século XXI: para uma reforma democrática e emancipatória da Universidade. São Paulo: Cortez. 